\title{
Pre-analytical Handling Problem
}

National Cancer Institute

\section{Source}

National Cancer Institute. Pre-analytical Handling Problem. NCI Thesaurus. Code C139524.

Incorrect pre-analytical handling of patient's sample by the user. 